\title{
El derecho económico y su papel como agente vinculante de la sociedad y la naturaleza en la perspectiva de un desarrollo integral'
}

\author{
Hernán Alberto Villa Orrego**
}

Recibido: 12 de mayo de 2017 • Aprobado: 26 de mayo de 2017

DOI: $10.22395 /$ ojum.v16n3la2

\begin{abstract}
RESUMEN
El presente artículo analiza el papel que debe cumplir el derecho económico como elemento articulador de las relaciones sociedadnaturaleza en la perspectiva de lograr un desarrollo integral para Colombia en el marco del Estado social de derecho. Este propósito implica establecer los orígenes del derecho económico a partir de las relaciones que surgen entre el derecho y la economía para presentarlo como una rama autónoma del derecho y distinguirlo del enfoque del análisis económico del derecho (AED). Desde esta visión el derecho económico se ha constituido en una importante herramienta para que el Estado intervenga en la economía con el objetivo de corregir los fallos del mercado, incluidos los generados por la contaminación. El gran desafío que enfrenta la humanidad en el siglo XXI es buscar soluciones a los problemas del deterioro ambiental, y en este sentido este escrito presenta al derecho económico como una alternativa para reequilibrar las relaciones sociedad-naturaleza.
\end{abstract}

Palabras clave: Derecho económico; medio ambiente; desarrollo integral; sociedad; naturaleza; análisis económico del derecho; Estado social de derecho; intervención estatal y contaminación ambiental.

Artículo resultado del proyecto de investigación titulado, "Biodiversidad: Protección de la biodiversidad como problema filosófico-jurídico". El autor del presente artículo participó en calidad de investigador y las instituciones que financiaron la investigación son: Universidad de Medellín, Universidad de Antioquia, Oregon State University y Zentrum fur Literturwissenschaft.

* Abogado de la Universidad de Antioquia. Economista de la Universidad Autónoma Latinoamericana. Magíster en Gerencia del Desarrollo Social de la Universidad de Antioquia. Maitrise de Sciences de L'education de la Université Paris-Est Créteil (ex-Université Paris 12) en Francia. Especialista en Derecho Público de la Universidad Autónoma Latinoamericana. Especialista en Derecho del Trabajo y de la Seguridad Social de la Universidad Pontificia Bolivariana. Especialista en Derecho del Medio Ambiente de la Universidad Externado de Colombia. Doctor en Derecho Procesal Contemporáneo de la Universidad de Medellín. Docente e investigador de tiempo completo e integrante del Grupo de Investigación: Derecho y Sociedad de la Facultad de Derecho y Ciencias Políticas en la Universidad de Antioquia, calle 70 № 52-21, Medellín, Colombia. E-mail: halberto.villa@udea.edu.co 


\title{
The economic law and its role as binding agent of society and the nature in the perspective of an integral development
}

\begin{abstract}
This article analyzes the role to be accomplished by the economic law as the articulating element of society-nature relationship in order to achieve an integral development for Colombia within the framework of the social right State. This purpose implies the establishment of the origins of economic law from the relationships which emerge between law and economics and presenting it as an autonomous branch of law and differentiating it from the approach of the economic analysis of law. From this point of view, the economic law has become an important tool to facilitate the governmental intervention in the economy in order to correct market failures, including the ones arising from contamination. The big challenge for humankind in the 21 st century is to search for the way to solve environmental damage issues; in this sense, this article shows the economic law as a good alternative to reach the balance of the relationships between society and nature.
\end{abstract}

Key words: Economic law; environment; integral development; society; nature; economic analysis of law; social right state; state intervention; environmental contamination. 


\section{INTRODUCCIÓN}

La sociedad contemporánea se enfrenta a una disyuntiva compleja de resolver: de un lado, la urgencia de satisfacer las necesidades individuales y colectivas de los seres humanos; y del otro, la obligación de realizar dicha tarea sin comprometer los recursos de las generaciones futuras, ni generar un impacto que, de forma puntual y acumulativa, pueda llegar a poner en riesgo la salud, el bienestar y hasta la misma vida de las generaciones actuales. El presente artículo contribuye a la investigación sobre la protección de la biodiversidad como problema filosófico-jurídico, en la medida en que plantea cómo el derecho económico podría hacer aportes significativos en la búsqueda de un modelo de desarrollo alternativo que se construya en una lógica que posibilite una mayor armonía en las relaciones: sociedad-naturaleza.

La investigación es de tipo cualitativo; la selección, organización y análisis de las fuentes de conocimiento se hizo de forma sistemática, y las decisiones de inclusión o exclusión de los materiales recopilados estuvieron condicionadas por la pertinencia de estos con el objeto de la investigación y de conformidad con la naturaleza crítica, dinámica y exploratoria que requiere una investigación cualitativa. Uno de los propósitos del presente artícu lo es que genere en aquellas personas que lo lean el interés de continuar haciendo aportes con nuevas investigaciones, en la misión fundamental de encontrar nuevos caminos que conduzcan a proponer opciones viables para la solución de los problemas del deterioro ambiental.
El artículo está estructurado en tres partes: en la primera, se aborda el derecho económico y las relaciones entre derecho y economía, haciendo una distinción entre el análisis económico del derecho y el derecho económico; en la segunda, se desarrolla más profundamente el concepto de derecho económico y su función en el Estado social de derecho; y en la tercera parte, se analiza al derecho económico como elemento articulador de las relaciones entre sociedad, medio ambiente y desarrollo.

\section{EL DERECHO ECONÓMICO Y LAS RELACIONES ENTRE DERECHO Y ECONOMÍA}

Estudiar el derecho económico como objeto de conocimiento implica necesariamente remitirse a las dos disciplinas científicas que lo integran: la economía y el derecho; pero cies el derecho económico una nueva área de conocimiento que goza de autonomía e independencia, o es simplemente la denominación teórica que se le da a una sumatoria de reflexiones académicas que surgen como consecuencia lógica de las relaciones que se establecen entre estas dos disciplinas? Como punto de partida, la respuesta a este interrogante será útil y necesaria en tanto permite definir y clarificar el objeto de estudio y delimitar su campo de actuación, antes de presentar y desarrollar cualquier temática que se pueda derivar de este saber interdisciplinario.

En un contexto general, se puede afirmar que antes de que surgiera teóricamente la denominación "derecho económico", los vínculos entre el derecho y la economía 
ya estaban presentes de forma práctica en las relaciones que emergen entre los miembros de la sociedad, hecho verificable mediante la observación de la realidad de la existencia del ser humano, el cual, al estar condicionado por la posibilidad de satisfacer sus necesidades, obligatoriamente pone en funcionamiento la lógica operativa de la ciencia económica en la medida en que tiene que utilizar racionalmente los recursos escasos que le suministra el entorno natural que lo rodea para obtener los bienes y los servicios necesarios para su supervivencia. De igual modo, la relación con las ciencias jurídicas será concomitante toda vez que este proceso estará sometido a una lógica de comportamiento soportada en un conjunto de normas que, acordes con un momento histórico, social y político, harán que las relaciones sociales de producción se acepten como legalmente válidas para esa población.

Es, además, necesario advertir que al binomio "economía y derecho" se debe agregar una tercera variable: la naturaleza, componente implícito y sin el cual sería prácticamente imposible este análisis; lo que en su conjunto permite establecer que entre la economía y el derecho, en su significación de ciencias o disciplinas del conocimiento, y el entorno o sistema natural que habitan los seres humanos, siempre han existido relaciones, pero que estas solo se consolidaron institucionalmente a partir del momento en que el derecho fue utilizado socialmente como el instrumento más adecuado para posibilitar la explotación de los recursos naturales y posteriormente la posesión disciplinada de la materia prima y los bienes, mediante la organización del proceso productivo en las etapas de extracción, producción, distribución, consumo y disposición final de residuos (Villa Orrego, 2013a, p. 107 ).

Es así como se establece un orden lógico de interacciones en las cuales primero se identifican los factores productivos originarios: la naturaleza y el hombre; y posteriormente, mediante el uso del lenguaje y en el marco de la interacción social y ambiental, emergen saberes como la filosofía, la teología, la historia, la antropología, la ciencia política, la sociología, la economía, el derecho, la psicología, entre otros que, sumados al surgimiento y avances de las ciencias exactas y naturales como la física, las matemáticas, la química, la biología, dieron origen, mediante la observación, el análisis, la experimentación y la investigación aplicada, al tercer factor productivo; el capital, entendido en su acepción económica, es decir, maquinaria, equipos, herramientas, infraestructura productiva y en general todo clase de tecnología incorporada al proceso productivo.

Las interacciones entre los seres humanos y de estos, a su vez, con su entorno natural han sido la constante a lo largo de la historia de la humanidad, lo cual implica que la sobrevivencia de la especie humana ha estado condicionada a dos elementos: primero, la convivencia social, y segundo, la transformación y el impacto a la naturaleza. En los últimos siglos y particularmente desde el siglo XVIII, el ser humano ha logrado un gran desarrollo en todas las ciencias y disciplinas del cono- 
cimiento, con el propósito de mejorar las condiciones de vida de la sociedad, pero, paradójicamente, el modelo económico capitalista (economía) que privilegia el capital sobre los otros dos factores productivos, humano y natural, y su sistema jurídico correlativo (derecho), que enaltece los derechos individuales por encima de los colectivos, no solo ha generado un deterioro en la naturaleza y en las condiciones de vida del ser humano, sino que, además, está poniendo en riesgo la vida en todas sus manifestaciones como consecuencia de los riesgos inherentes de los avances científicos y tecnológicos.

Ahora bien, desde el punto de vista teórico algunos autores han descrito específicamente las relaciones entre el derecho y la economía de la siguiente manera: "La economía fija y jerarquiza los fines y señala los medios económicos mediante los cuales pueden alcanzarse aquellos. Pero el derecho, traduciendo todo ello en normas jurídicas, se encarga de disciplinar el proceso" (Moore Merino, 1962 citado por Sierralta, 1968, p. 17). "Si la economía propone, la ley debe disponer. Los fines del economista se convierten en política solamente a través de los medios suministrados por la ley" (Rostow, 1962, citado por Sierralta, 1968, p. 17).

Otros autores establecen una relación implícita entre el derecho y la economía directamente desde la perspectiva del derecho económico; es el caso del profesor Leguizamón quien desde un enfoque sustancial determina que "la función del derecho en el proceso productivo ya descrito es la de mantener en completa armonía todas las relaciones mercantiles que se adelantan; para esto se apoya en su herramienta natural: "la norma Jurídica"” (Leguizamón A., 2002, p. 20). Posteriormente, desde la visión procesal del derecho, afirma que: "la norma jurídica no acaba su función con la simple regulación de estas actividades; también se encarga de hacer cumplir las obligaciones naturales y las contractuales en cada negocio o actividad económica en particular" (Leguizamón A., 2002, p. 21).

Una vez presentadas estas breves consideraciones acerca de las relaciones entre economía y derecho, desde su observancia tanto práctica como teórica, será pertinente determinar el vínculo que tienen estas con el derecho económico. Es importante establecer que las relaciones entre la economía y el derecho han dado lugar a una variada posibilidad de teorías, enfoques y discusiones, y en ese contexto, el derecho económico es el resultado de solo una forma particular de relación. En este sentido, se pueden encontrar dos categorías de relaciones entre la economía y el derecho que se sintetizan de la siguiente manera:

A. Los vínculos entre la ciencia jurídica y económica: en esta categoría se toman ambas áreas del conocimiento como ciencias y posteriormente se analizan las clases de relación que pueden surgir entre ellas, a saber: 1) De causalidad, en la que se establece que la economía prima sobre el derecho en la medida en que los hechos económicos son el origen y la causa de las demás manifestaciones que surgen 
en la sociedad, incluido el derecho; 2) De interacción, en la que se presentan unos vínculos recíprocos de acción y reacción, de manera que un cambio en alguna de las disciplinas, bien sea jurídico o económico, genera un efecto en la otra y, 3) De integración, en esta se da una relación de complementariedad, en razón a que tanto la economía como el derecho actúan de manera coordinada para cumplir con los fines sociales en una comunidad (Sierralta, 1988, pp. 12-15).

B. El derecho y la economía tomados como ciencia y objeto de conocimiento: en esta segunda clase de relaciones se forma un conjunto integrado por la economía y el derecho; el tipo de relaciones que surjan dependerá del papel que asuma una u otra disciplina. De esta forma, se obtienen dos subconjuntos: en uno de ellos, una disciplina actuará como ciencia, analizando a la otra como objeto de conocimiento; y en el otro, se intercambian las funciones. Esto da lugar a dos formas distintas de relación que, dependiendo de los roles asumidos, se denominarán "análisis económico del derecho (AED)" o "derecho económico", como sigue:

\subsection{Análisis económico del derecho (AED)}

En el tipo de relaciones que dan lugar a esta denominación, la economía asume su condición de ciencia y con fundamento en todas sus herramientas metodológicas

\footnotetext{
*Análisis Económico del Derecho (AED).
}

somete en su lógica analítica al derecho, el cual adoptará como institución, el rol de objeto de estudio. El campo del AED es muy amplio; sin embargo, se puede entender de manera general que las relaciones que se establecen entre la economía y el derecho se construyen en una lógica en la cual, "la economía ofrece una teoría del comportamiento para pronosticar cómo responderán los individuos ante los cambios de las leyes. (...) Además la economía ofrece un criterio normativo útil para la evaluación del derecho y de las políticas públicas" (Cooter \& Ulen, 1998, p. 14.) En síntesis, se puede afirmar que el principal objetivo del AED es "aplicar los métodos de la ciencia económica al derecho" (Bullar G, 2003, p. 37) y para ello, "Utiliza los supuestos de la microeconomía para explicar el comportamiento de los individuos ante la ley" (Rubio, 2007, p. 45).

Frente al origen del AED existe una tendencia que lo presenta como una creación de la Escuela de Chicago en 1960 (Bullar G., 2003, p. 37); sin embargo, esta postura deja por fuera importantes estudios que conducen al nacimiento de la ciencia económica y que pueden considerarse como la base fundamental de lo que en la actualidad se conoce como AED (Cabanellas, 2006, p. 23). En este sentido para Richard Posner, un destacado exponente contemporáneo de este movimiento, el análisis económico del derecho tiene dos ramas, las cuales se remontan a los orígenes de la economía en el siglo XVIII; la primera, está asociada a Adam Smith (1723-1790), porque sus estudios sobre los efectos económicos de la legislación mercantilista fueron realmente análisis 
económicos aplicados a las leyes que regulan el mercado (sistema económico); y la segunda rama tiene sus orígenes en los trabajos adelantados por Jeremy Bentham (1748-1832) porque realizó análisis económicos de las leyes que regulan aspectos diferentes de los mercados, como el matrimonio, los accidentes, la delincuencia, la contaminación, los procesos políticos y legales, entre otros (Roemer, 2001, p. 6).

En la segunda variante del AED, de asuntos ajenos al mercado, no se puede desconocer la obra de Cesare Beccaria (1764) porque, al realizar "el análisis de los delitos y las penas, lejos de la costumbre de su época, desde la perspectiva del daño y el beneficio que proporcionan a la sociedad" (Torres L., 1987, p. 16), contribuyó a que se "abandonaran las justificaciones más o menos irracionales de la existencia de las penas, (...) y que más bien se persiguieran criterios utilitarios, tales como la efectividad de la pena en la disuasión de los futuros delincuentes y el costo de la Administración de Justicia, junto con el grado de eficiencia de la misma" (Nuñez, 2000, p. 69).

En épocas más cercanas, el AED tuvo un renacimiento gracias a los escritos de Gary Becker sobre discriminación racial (1959) y economía del crimen y el castigo (1968); el ensayo de Ronald Coase (1960) acerca del problema de los costos sociales; y el primer artículo de Guido Calabresi (1961) sobre distribución de riesgos y ley de agravios (Posner, 2002, p. 68). Estos trabajos fueron catalogados como importantes manifestaciones contemporáneas del AED porque con el fin de llegar a sus conclusiones, utilizaron un "método -en este caso económico- para analizar aquellas conductas humanas que se encuentran relacionadas, de algún modo, con el derecho" (Cossio Díaz, 2002, p. 228).

\subsection{Derecho económico}

En las relaciones que dan lugar a esta calificación, se invierten los roles presentados en el AED, de forma que el derecho asume su condición de ciencia y con fundamento en sus instrumentos teóricos y metodológicos procura atrapar en su lógica analítica a la economía, la cual adoptará como institución el rol de objeto de estudio. Es decir, el derecho económico tiene como pretensión fundamental someter los asuntos económicos, que sean susceptibles de regulación, a la dinámica funcional del derecho, mediante la creación de normas y principios dirigidos a disciplinar las relaciones entre las instituciones económicas de la sociedad. En este orden de ideas, para el profesor Rojo (1980) citado por Ariño Ortiz (2003):

$$
\begin{aligned}
& \text { [...] el derecho económico se pre- } \\
& \text { senta así como un conjunto de } \\
& \text { normas jurídicas relacionadas entre } \\
& \text { sí, no solo con arreglo a simples cri- } \\
& \text { terios de jerarquía, sino también en } \\
& \text { función de la estructura del sistema } \\
& \text { económico y de la conexión y re- } \\
& \text { laciones de dependencia entre los } \\
& \text { distintos sectores del sistema (pp. } \\
& 258 \text { y 259). }
\end{aligned}
$$

Ni desde la perspectiva del AED ni desde la del derecho económico, se discute la jerarquía o la dominación de la una sobre la otra; simplemente se definen los roles que 
necesitan asumir en una u otra dirección y se reconoce la necesidad, importancia y validez científica, de los resultados obtenidos en la realización de las investigaciones en ambos enfoques; sin embargo, debe quedar claro que, aunque el AED y el derecho económico son dos formas de relación entre la economía y el derecho, no son lo mismo.

En este sentido Márquez (2005) explica:

[...] como podemos ver, las relaciones antes descritas tienen su origen en los distintos modos de comprender las palabras "derecho" y "economía". Por ello, cuando se hace derecho económico, que es la resultante de un tipo de relación entre el derecho y la economía, no se está haciendo análisis económico del derecho. Por lo mismo, cuando se está haciendo análisis económico del derecho no se hace derecho económico. Son disciplinas distintas, con objetivos y modos de comprender el derecho y la economía distintos (p. 37).

Ahora bien, es posible establecer relaciones entre el derecho económico y el AED sin que cada una de estas disciplinas pierda su esencia teórica y metodológica; en este sentido, la realización de estudios de análisis económico del derecho podrían conducir a la creación de nuevas estructuras jurídicas de derecho económico. Fue el caso de Adam Smith, quien "al observar las conspiraciones que se urdían para restringir el comercio internacional, dio pie a la creación de una legislación antimonopólica" (Roemer, 2001, p. 6) y con ello, además de otras reflexiones teóricas, sentó las bases para el nacimiento de la escuela clásica del liberalismo económico. A su vez, el derecho económico puede generar modificaciones estructurales en la economía y en la política, y con ello mejorar las condiciones de vida de la población desde las dimensiones económica, social y ambiental; en este último enfoque está centrado el objetivo del presente escrito. Por lo tanto, en lo sucesivo se dará especial atención al derecho económico.

\section{EL DERECHO ECONÓMICO Y SU FUNCIÓN EN EL ESTADO SOCIAL DE DERECHO}

La función del derecho económico se puede inferir, de manera general, a partir de la utilidad que brinda para el adecuado funcionamiento de las instituciones esenciales del sistema económico; o deducir, de forma especial, cuando se reconoce la necesidad de las disposiciones mediantes las cuales el poder estatal interviene en los asuntos económicos con el objetivo de alcanzar ciertas metas o propósitos que sean convenientes para la sociedad. Además, es fundamental tener presente que en materia económica todo clase de organización política, "sea capitalista, socialista o mixta, requiere para su funcionamiento armonioso cierto número de normas jurídicas que permitan a los diferentes actores de la vida económica la adquisición y el uso de los factores de producción, de los productos y de los servicios de una manera segura" (Velilla Moreno, 2013, p. 101).

En este orden de ideas, la funcionalidad del derecho económico en las sociedades 
modernas estará condicionada por el tipo de Estado y por el sistema económico que una comunidad decida establecer constitucionalmente. Sobre este asunto el profesor Witker (1985) afirma: "el sistema jurídico, conforma aquel subsistema de control social, que dimana del Estado en forma de normas jurídicas y disciplina al cuerpo social con base en una ideología de aceptación" (p. 24) y agrega que a cada sistema económico le corresponderá un respectivo sistema jurídico. En la historia reciente se identifican dos modos de producción: el capitalismo y el socialismo; sin embargo, dentro del capitalismo se pueden reconocer varias escuelas del pensamiento político y económico, las cuales han oscilado entre el puro liberalismo económico (economía de libre mercado) y un marcado intervencionismo estatal (economía mixta).

Estos sistemas económicos han estado acompañados de sus respectivos sistemas jurídicos, los cuales constitucional y legalmente han definido el papel que el Estado debe asumir. La manifestación del derecho económico desde la perspectiva del intervencionismo económico estatal en el capitalismo surge después de la Gran Depresión de 1929, ante la incompetencia de la economía de libre mercado para autorregular y corregir sus desequilibrios macroeconómicos (Márquez Robledo, 2007, p. 16), en este caso, el desempleo. Con esta situación y gracias a las teorías de Keynes se replanteó el rol del Estado en la economía, y "el papel de las finanzas públicas como instrumento estabilizador empezó a cambiar" (Restrepo, 2012, p. 36).
En términos generales, el modelo a ultranza de economía de libre mercado ha mostrado cronológicamente los siguientes fallos e inconsistencias: primero (S. XVIII y XIX), el surgimiento de monopolios económicos y las profundas inequidades sociales, generados en la implementación del modelo; segundo (S. XX y XXI), los problemas de desempleo, inflación y estanflación, fruto de la inestabilidad macroeconómica de los mercados; y tercero (S. XX), la contaminación ambiental, la cual se constituye en el principal problema y el reto más importante que enfrenta la humanidad en el siglo XXI.

En estas circunstancias, se pueden inferir a su vez, tres situaciones: 1) El derecho económico se constituye en el principal instrumento con el que cuenta el Estado para intervenir la economía y corregir los fallos de mercado, incluidos los que generan deterioro del medio ambiente; 2) El derecho económico no está dirigido exclusivamente a resolver los problemas derivados de la contaminación y, por lo tanto, no puede ser equiparable a derecho ambiental; 3) Todo el conjunto de normas que busca proteger el medio ambiente y que se constituye en el derecho ambiental es realmente derecho económico.

En el siglo pasado se discutió mucho acerca de la pertinencia o no de la intervención del Estado en la economía mediante el uso de la política económica; en la actualidad esa controversia no es viable porque hoy, por el contrario, hay consenso acerca de esta importante tarea estatal y, por lo tanto, el debate gira en torno a los tipos de intervención, las 
áreas de actuación y el nivel de intensidad con que tendrá que actuarse. Por tal razón, en la Carta Política de Colombia en 1991, se pretendió corregir los problemas anteriormente mencionados con una ponderación entre libertad de mercado e intervención del Estado y no se consagró expresamente ningún sistema económico en general. Esto se debe a que su construcción fue el "fruto del consenso entre diversas fuerzas orientadas por las más variadas ideologías, a tal punto que es verdad reconocida por todos, que no es viable encontrar en la nueva Carta una concepción idéntica que oriente la totalidad de sus normas" (Plazas Vega, 2006, pp. 213 y 214).

Posteriormente, la práctica constitucional ha permitido que la Corte determine tres clases de intervencionismo económico estatal a saber:

\begin{abstract}
[...] conformativa, que establece los requisitos de existencia, formalización y funcionamiento de los actores económicos; finalista, que señala los objetivos generales o las metas concretas a las cuales han de propender los actores económicos; y condicionante, que propiamente fija las reglas del juego del mercado o de un sector económico (Corte Constitucional de Colombia, 2003).
\end{abstract}

En este sentido, la función del derecho constitucional económico en la perspectiva de alcanzar el anhelado Estado social de derecho está consagrada en la Carta Política del 1991 y establece que es deber del Estado colombiano intervenir:
1) Para regular, racionalizar y estabilizar la economía, lo cual implica promover la libre competencia económica, dar pleno empleo a los recursos humanos y mantener la capacidad adquisitiva de la moneda².

2) Para redistribuir la riqueza y generar desarrollo social, lo cual se logra adoptando medidas en favor de grupos discriminados y marginados; asegurando que todas las personas, en particular las de menores ingresos, tengan acceso efectivo a los bienes y servicios básicos y, en general, mejorando la calidad de vida de los habitantes ${ }^{3}$.

3) Para que haya crecimiento y desarrollo económico, lo que supone fortalecer las organizaciones solidarias, estimu lar el desarrollo empresarial, promover la productividad y competitividad y lograr el desarrollo armónico de las regiones ${ }^{4}$

4) Para alcanzar el desarrollo sostenible, lo cual se consigue materializando la función ecológica que debe tener la propiedad privada, planificando el manejo y aprovechamiento de los recursos naturales y, en general, logrando la preservación de un medio ambiente sano ${ }^{5}$.

En los términos de los artículos 333, 334 y 373 de la Constitución Política de Colombia de 1991.

3 En los términos de los artículos 13, 334 y 366 de la Constitución Política de Colombia de 1991

4 En los términos de los artículos 333, 334 y 366 de la Constitución Política de Colombia de 1991.

5 En los términos de los artículos 58, 79, 80, 334 y 366 de la Constitución Política de Colombia de 1991. 


\section{EL DERECHO ECONÓMICO COMO ELEMENTO ARTICULADOR DE LAS RELACIONES ENTRE SOCIEDAD, MEDIOAMBIENTE Y DESARROLLO}

Uno de los desafíos más importantes que enfrenta la sociedad de hoy, tanto en el ámbito nacional como en el internacional, es encontrar una forma equilibrada de conciliar dos realidades: la satisfacción de las necesidades de la población, y la preservación del medio ambiente. Esto necesariamente implicará reconstruir las relaciones sociedad-naturaleza, las cuales, y como consecuencia de la adopción de un modelo de desarrollo fundado privilegiadamente en el crecimiento económico a ultranza, se tornaron insostenibles. Esta situación está dejando un medio ambiente deteriorado con consecuencias ampliamente conocidas por todos como la contaminación del agua, el aire y la tierra, la pérdida de biodiversidad, la deforestación, el cambio climático y el aumento y exacerbación de enfermedades de todo tipo, con lo cual se está poniendo en peligro el bien más preciado y esencial de todos: la vida (Villa Orrego, 2013a, pp. 27 y 159).

Ahora bien, el orden entre las relaciones naturaleza, sociedad y desarrollo está determinado por el conjunto de normas de derecho económico que definen las condiciones bajo las cuales se darán las relaciones sociales y ambientales en el proceso de extracción, producción, distribución, consumo y disposición final de residuos, en el escenario de una determinada clase de desarrollo. Por lo tanto, es evidente que una parte de la solución al problema está asociada a la creación de una legislación más adecuada a esta realidad que induzca correlativa y complementariamente a un cambio en la sociedad y que permita la incorporación de una nueva cultura medioambiental (Villa Orrego, 2013b, pp. 296 y 297). Este análisis convoca a la reflexión sobre el tipo de desarrollo que necesita esta sociedad, porque de acuerdo con Novoa (1987) citado por Velilla (2013):
[...] si se trata de buscar los in- strumentos jurídicos mejores para un desarrollo económico avanzado dentro de los marcos de un Estado social de derecho, hemos de precisar, ante todo, cual ha de ser ese desarrollo económico, para luego indagar sobre las formas como puede ser instrumentado y seleccionar, por fin, los instrumentos más apro- piados" (p. 103).

En las actuales circunstancias es evidente que el modelo vigente de desarrollo y el ordenamiento jurídico que lo implementa, tanto al nivel nacional como al internacional, no está permitiendo ver alternativas de solución al problema de la contaminación; de hecho, el funcionamiento actual del modelo muestra una disyuntiva entre protección del medio ambiente y generación de empleo, con lo cual la relación sociedad-naturaleza entra en un terreno de rivalidad. Esta premisa es fácilmente verificable, basta analizar la siguiente realidad: con la pasada crisis económica mundial (2008), la cual no logra resolverse adecuadamente, la economía mundial decreció y, con esto, paradójicamente para bien de la naturaleza, disminuyeron las 
emisiones contaminantes y la irracional explotación de los recursos naturales.

Desafortunadamente para el hombre, con la crisis económica el desempleo aumentó y la situación ambiental nuevamente empeoró, porque en la actualidad la política económica en la mayoría de los países del mundo está orientada a la reactivación de la economía para la generación de empleo, dejando en un segundo plano la problemática ambiental. En Colombia la situación no es diferente; se puede observar la coyuntura actual de la minería (tanto artesanal como industrial) y su ambivalencia entre la contaminación, los riesgos que genera, y la decisión gubernamental de adoptarla como una de las locomotoras del desarrollo, a lo que se suman las manifestaciones de los mineros invocando su derecho al trabajo, aun a costa de su propia vida.

Por todo lo anterior, se requiere un desarrollo sostenible integral, entendido como una construcción colectiva donde se armonicen las potencialidades económicas, las necesidades sociales y los deberes ambientales, bajo una nueva relación sociedad-naturaleza en la cual, el subsistema económico y social funcione condicionado a los límites y la lógica de un sistema mayor que es el ecosistema (Martínez Alier, 1994). Este tipo de propuestas plantean un desafío enorme para su materialización, pero afortunadamente existen investigaciones en economía, que con apoyo de la ecología, la biología, la física y la química, entre otras áreas del conocimiento, presentan alternativas interesantes que demuestran que esta nue- va dinámica podría ser una realidad, como sugiere el economista Gunter Pauli, quien en su libro La economía azul, plantea: "Si nuestras economías se desarrollaran con la naturaleza como modelo, podríamos emplear la energía y los recursos de manera eficiente y sin generar residuos, y además crearíamos cientos de millones de puestos de trabajo" (Pauli, 2012, p. 37)

Los avances que se han dado en materia de modelos alternativos de desarrollo sostenible desde las ciencias antes mencionadas, en particular la economía, necesitan correlativamente un progreso en el campo jurídico; por tal razón, es necesario conformar grupos de estudio y formular investigaciones interdisciplinarias que tengan como objetivo inmediato, mejorar las relaciones entre la sociedad y la naturaleza, con base en el derecho económico existente y, a mediano y largo plazo, discutir y revisar los actuales sistemas jurídicos, políticos y económicos en aras de proponer reformas legislativas que comprendan estas nuevas visiones del desarrollo, pudiendo armonizar la protección del medio ambiente, la generación de empleo y el desarrollo integral del ser humano en un escenario de libre competencia económica bajo parámetros claros de sostenibilidad, tanto en el contexto nacional como en el internacional. En este sentido, le corresponderá
[...] al derecho económico, por las grandes facultades que posee y su enorme poder regulador, que trasciende todos los campos de las actividades sociales, ejercer un papel de la mayor importancia para obtener los fines y los obje- 
tivos propios de sus principios fundamentales, que se encuentran en perfecta interacción con el desarrollo de las políticas ambientales (Leguizamón A., 2002, p. 339).

En este orden de ideas, el derecho económico debe ser entendido como un instrumento al servicio del reconocimiento legal que el modelo político y económico contemple para la protección del medio ambiente y de esta manera reivindicar los derechos a un medio ambiente sano ya reconocidos al hombre desde una perspectiva funcional o instrumental del derecho ambiental; sin embargo, es necesario abrir formalmente el debate, al nivel nacional y al internacional, acerca de la necesidad de elevar al sistema natural (seres humanos y naturaleza) a la categoría integral de sujeto de derechos en un acto de vindicación de derechos para la naturaleza (valoración intrínseca) en forma complementaria con los derechos humanos.

Ahora bien, para enriquecer el anterior debate en cuestión y, asimismo, plantear una posible ruta de materialización en el marco del desarrollo de la presente investigación o de otras encaminadas a proponer modelos alternativos al desarrollo, es necesario e importante considerar propuestas como las planteadas por los pueblos indígenas ${ }^{6 *}$, que definen el desarrollo integral como:

6 Esta propuesta alternativa al desarrollo es apropiada del concepto de desarrollo integral contenido en la Ley de la Madre Tierra. Ley 300 de 2012 del Estado Plurinacional de Bolivia.
[...] el proceso continuo de generación e implementación de medidas y acciones sociales, comunitarias, ciudadanas y de gestión pública para la creación, provisión y fortalecimiento de condiciones, capacidades y medios materiales, sociales y espirituales, en el marco de prácticas y de acciones culturalmente adecuadas y apropiadas, que promuevan relaciones solidarias, de apoyo y cooperación mutua, de complementariedad y de fortalecimiento de vínculos edificantes comunitarios y colectivos para alcanzar el Vivir Bien en armonía con la Madre Tierra (Estado Plurinacional de Bolivia. Asamblea Legislativa Plurinacional, 2012).

En ese mismo sentido y para una mejor comprensión del alcance del desarrollo integral planteado en la Ley de la Madre Tierra, es fundamental conocer los conceptos de Madre Tierra y Vivir Bien que se plasmaron en los dos primeros párrafos del artículo 5:

Madre Tierra: Es el sistema viviente dinámico conformado por la comunidad indivisible de todos los sistemas de vida y los seres vivos, interrelacionados, interdependientes $y$ complementarios, que comparten un destino común. La Madre Tierra es considerada sagrada; alimenta $y$ es el hogar que contiene, sostiene $y$ reproduce a todos los seres vivos, los ecosistemas, la biodiversidad, las sociedades orgánicas y los individuos que la componen (Estado Plurinacional de Bolivia. Asamblea Legislativa Plurinacional, 2012). 
El Vivir Bien (Sumaj Kamaña, Sumaj Kausay, Yaiko Kavi Päve): Es el horizonte civilizatorio y cultural alternativo al capitalismo y a la modernidad que nace en las cosmovisiones de las naciones y pueblos indígena originario campesinos, y las comunidades interculturales y afrobolivianas, $y$ es concebido en el contexto de la interculturalidad. Se alcanza de forma colectiva, complementaria y solidaria integrando en su realización práctica, entre otras dimensiones, las sociales, las culturales, las políticas, las económicas, las ecológicas, y las afectivas, para permitir el encuentro armonioso entre el conjunto de seres, componentes y recursos de la Madre Tierra. Significa vivir en complementariedad, en armonía y equilibrio con la Madre Tierra y las sociedades, en equidad y solidaridad y eliminando las desigualdades y los mecanismos de dominación. Es Vivir Bien entre nosotros, Vivir Bien con lo que nos rodea $y$ Vivir Bien consigo mismo (Estado Plurinacional de Bolivia. Asamblea Legislativa Plurinacional, 2012).

Finalmente, es importante recordar que la ONU aprobó en 1986 la "Declaración sobre el Derecho al Desarrollo" y que una parte fundamental del cumplimiento de este derecho está vinculado necesariamente al principio de justicia y equidad ambiental, según el cual, "todos los seres humanos, indistintamente, tienen derecho al acceso y uso de los recursos del planeta indispensables a la vida" (Grzybowski, 2005, p. 87). Con base en esta premisa el nuevo derecho económico debe estar construido sobre la base de dos pilares: primero, "el bienestar de la humanidad está indisolublemente vincu- lado al desarrollo con la naturaleza; -por tanto - se hace inaplazable un contrato natural basado en la alianza de la ciencia, el desarrollo y la preservación del medio ambiente" (Mínguez E Ortega, 2003, p. 272); y segundo, el papel de la educación es fundamental para que la sociedad comprenda que la forma en que se establecen las relaciones sociedad-naturaleza es el resultado de aprendizajes históricos que deben estar condicionados por las circunstancias especiales que vive una sociedad en un momento determinado. Por lo tanto, estas dos perspectivas serán cruciales si se desea garantizar el derecho al desarrollo mediante una adecuada protección de la vida, presente en los ecosistemas del planeta.

\section{CONCLUSIONES}

Las relaciones entre la economía y el derecho pueden dan origen a dos campos distintos del conocimiento; esta categorización dependerá del rol que cada una de estas disciplinas adopte; en aquellas investigaciones donde la economía asuma la posición de ciencia y el derecho sea tomado como objeto de investigación (con la finalidad de plantear soluciones, desde el punto de vista económico, a un problema jurídico), esos resultados estarán haciendo referencia al análisis económico del derecho (AED); por el contrario, cuando el derecho desempeñe la función de ciencia jurídica y analice los asuntos problemáticos de la economía con el objetivo de proponer alternativas desde el campo específico del saber jurídico, entonces esos hallazgos pertenecerán a la categoría del derecho económico. 
Tanto el AED como el derecho económico pueden resultar útiles para plantear alternativas para los actuales problemas del deterioro ambiental; sin embargo, el derecho económico (entendido como el principal instrumento que faculta al Estado para intervenir en la economía y particularmente en el fallo de mercado que genera contaminación) es el que tiene un rol más protagónico en la búsqueda de propuestas de solución y mitigación a esta problemática, mediante la reflexión y posterior creación de un ordenamiento jurídico que posibilite unos mecanismos de regulación directa y control, que sean más efectivos que los existentes, y la implementación de instrumentos de política económica conducentes a inducir y motivar en los agentes económicos cambios en sus conductas en la perspectiva de contribuir progresivamente a lograr una relación más equilibrada entre la sociedad y la naturaleza.

Es evidente que entre la naturaleza, la economía y el derecho, se entrelazan unas relaciones indisolubles, las cuales se materializan dentro del modelo de desarrollo económico que incorpora una sociedad en un momento determinado. En las actuales condiciones es necesario trabajar y adelantar investigaciones desde las distintas áreas y disciplinas del conocimiento, en la construcción y adopción de un modelo alternativo de desarrollo que propicie una lógica encaminada a la descolonización de las ideas del progreso occidental (la cual es inviable en el mediano y largo plazo), y fomente la adopción de una mirada que apunte a un desarrollo integral donde se pueda incorporar en la sociedad una cosmovisión sistémica, holística y comprensiva que integre la realidad finita de los recursos del planeta y la posibilidad infinita de la vida.

La premisa planteada por la economía ecológica, en relación con que el sistema económico debería funcionar limitado y condicionado por un sistema mayor que es el ecosistema, y en esa misma dirección, las reflexiones, tan coherentes y profundas, presentados por la mayoría de las comunidades indígenas en todo el planeta, invitan a pensar, construir e implementar una alternativa de desarrollo sustentado, de un lado, en la lógica de las dinámicas funcionales y de los ciclos de vida de la naturaleza, y del otro, en una organización social que opere alrededor del "horizonte civilizatorio y cultural" del "Vivir Bien" en el seno de la concepción de la "Madre Tierra" entendida como el sistema que da soporte a la vida en todas sus manifestaciones. En este sentido, la vinculación de las ciencias jurídicas y especialmente del derecho económico será necesaria y podrá aportar significativamente, si se traza desde esta visión, el objetivo fundamental de vincular la naturaleza y la sociedad en la perspectiva de alcanzar un desarrollo armónico e integral.

\section{REFERENCIAS BIBLIOGRÁFICAS}

Ariño Ortiz, G. (2003). Principios de derecho público económico. Bogotá: Universidad Externado de Colombia.

Bullar G. A. (2003). Derecho y Economía. Lima: Palestra Editores. 
Cabanellas, G. (2006). Análisis económico del Derecho. Evolución histórica. Metas e instrumentos. En: Kluger, V. (Comp.). Análisis económico del Derecho. Buenos Aires: Ed. Heliastra.

Cooter, R., E Ulen, T. (1998). Derecho y Economía. México D. F: Fondo de Cultura Económica.

Corte Constitucional de Colombia. (2003). Sentencia C-150 de 2003. Magistrado ponente: Manuel Cepeda Espinosa.

Cossio Díaz, J. (2002). Derecho y análisis económico. México, D.F.: Fondo de Cultura Económica e ITAM.

Estado Plurinacional de Bolivia. Asamblea Legislativa Plurinacional. (15 de octubre de 2012). Ley 300. Ley Marco de la Madre Tierra y Desarrollo Integral para Vivir Bien.

Grzybowski, C. (Diciembre de 2005). Derecho al desarrollo: democracia solidaria. En Revista Foro. Bogotá. Diciembre de 2005. № 56.

Leguizamón A., W. (2002). Derecho económico. Bogotá: Ediciones Doctrina y Ley.

Márquez Escobar, C. (2005). Análisis económico del derecho. Bogotá: Fundación Cultural Javeriana de Artes Gráficas.

Márquez Robledo, F. (2007). Anotaciones sobre derecho económico y derecho de la competencia. 2a ed. Bogotá: Fundación Cultural Javeriana de Artes Gráficas.

Martínez Alier, J. (1994). De la economía ecológica al ecologismo popular. 2a ed. Barcelona: ICARIA Editorial, S. A.

Mínguez, R., E Ortega, P. (2003). Educar para una cultura medioambiental. (España, Editor) Obtenido de Revista de educación. $N^{\circ}$ Extra 1: http://www.doredin.mec.es/ documentos/008200430105.pdf
Moore Merino, D. (1962). Derecho económico. Santiago de Chile: Editorial Jurídica de Chile.

Novoa M., E. (1987). Instrumentos jurídicos para una política económica de avanzada, el derecho como factor de cambio social. Buenos Aires: Ed. Depalma.

Núñez, A. (2000). Antecedentes y principios fundamentales del análisis económico de la ley. En Colección Derecho Económico II. Bogotá: Universidad Externado de Colombia.

Pauli, G. (2012). La economía azul. 4a ed. México, D. F.: Tusquets Editores S.A.

Plazas Vega, M. A. (2006). Derecho de la hacienda pública y derecho tributario. Tomo I. Bogotá: Editorial Temis.

Posner, R. (2002). Usos y abusos de la teoría económica en el derecho. En: Roemer, A. (Comp.). Derecho y economía: Una revisión de la literatura. México, D. F.: Fondo de Cultura Económica, ITAM y Sociedad Mexicana de Geografía y Estadística.

Restrepo, J. C. (2012). Hacienda pública. 9a ed. Bogotá: Universidad Externado de Colombia.

Roemer, A. (2001). Introducción al análisis económico del derecho. México, D. F.: Ed.Fondo de Cultura Económica, ITAM y Sociedad Mexicana de Geografía y Estadística.

Rojo, Á. (1980). El derecho económico como categoría sistémica. En Revista de Legislación y Jurisprudencia. España: T. LXXX, 2a época. No 3 .

Rostow, E. (1962). Planteamiento para la libertad. Buenos Aires: Editorial Jurídica Omeba.

Rubio, M. (2007). Economía jurídica. Introducción al análisis económico del derecho iberoamericano. Bogotá: Universidad Externado de Colombia. 
Sierralta, A. (1988). Introducción a la Juseconomía. Lima: Fondo Editorial de la Pontificia Universidad Católica del Perú.

Torres L., J. (1987). Análisis económico del Derecho. Madrid: Editorial Tecnos, S. A.

Velilla Moreno, M. A. (2013). Introducción al derecho económico y de los negocios. Bogotá: Editorial Planeta Colombiana S. A.

Villa Orrego, H. A. (2013a). Derecho internacional ambiental. Un análisis a partir de las relaciones entre economía, derecho y medioambiente. Medellín: Editorial Universidad de Medellín y Editorial Astrea.

Villa Orrego, H. A. (2013b). Cultura medioambiental y derecho procesal. En Proceso Judicial y cultura. Una mirada global. Medellín: Editorial Universidad de Medellín.

Witker, J. (1985). Derecho económico. México: HARLA S. A. 
